Digilec 6 (2019), pp. 115-121

Fecha de recepción: 26/08/2019

Fecha de aceptación: 26/10/2019

DOI: https://doi.org/10.17979/digilec.2019.6.0.5855

(cc) BY-SA

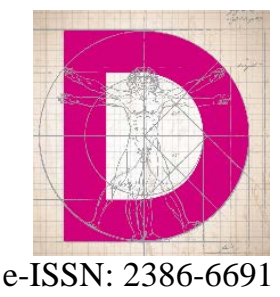

\title{
UN ESTUDIO DE LOS TOCADOS QUE APARECEN EN LA ERMITA DE SAN BARTOLOMÉ, CAÑÓN DE RÍO LOBOS, SORIA
}

A STUDY OF THE 13TH CENTURY HEADDRESSES. SAN BARTOLOMÉ HERMITAGE, CAÑÓN DE RÍO LOBOS, SORIA

\section{Consuelo SANZ DE BREMOND LLORET *}

Investigadora de la indumentaria histórica

\section{Resumen}

Presentamos en este trabajo un estudio sobre tres tocados que aparecen en la ermita de San Bartolomé, en el Cañón de Río Lobos (Soria), construida en el primer cuarto del siglo XIII, y que estuvieron de moda durante todo ese siglo. Es de interés un tocado femenino que, si bien aparece en Francia, tendrá en Castilla una evolución única y original.

Palabras clave: San Bartolomé; siglo XIII; tocados; bonetillo; capirote; cofia.

\begin{abstract}
We present in this work a study on three headdresses that appear in San Bartolomé Hermitage, Cañon de Río Lobos (Soria), built in the first quarter of the 13th century, and that were in fashion throughout that century. It is of interest a female headdress that although it appears in France will have a unique and original evolution in Castile.
\end{abstract}

Key Words: San Bartolomé; 13th century; headdresses; bonnet; chaperon; coif. 


\section{INTRODUCCIÓN}

La ermita de San Bartolomé de Ucero es un templo con planta de cruz latina, y ábside semicircular. Las capillas laterales del crucero son más bajas que la nave central y se iluminan con rosetones abocinados en el exterior y cubiertos con una celosía en piedra. La nave se cubre con bóveda de medio cañón apuntado, mientras que en el ábside la bóveda es gótica (Enríquez, 1998).

Toda la construcción fue realizada en sillería de piedra caliza y destacan los numerosos canecillos, algunos lisos, aunque en el brazo sur del crucero y en la fachada se decoran con motivos figurativos y geométricos. Varios investigadores han publicado estudios que relacionan directamente las figuras representadas en los canecillos con el mundo templario y esotérico, sin profundizar en las figuras objetos de este estudio, situadas dos de ellas en un lateral de la portada y otra en uno de los canecillos que queda sobre la misma portada.

\section{BONETILLO}

Tocado que denominaremos de cuerpo bajo o de cuerpo alto según la altura del mismo. Un ejemplo de los primeros bonetillos de cuerpo bajo en la Península Ibérica lo tenemos en el sepulcro de doña Sancha fechado en 1096, que se encuentra en el Convento de Benedictinas de Jaca, Huesca. En el siglo XIII se van a estilar bonetillos realizados con un cuerpo cilíndrico. Este cuerpo se hacía de pergamino (Gómez Moreno, 1946; Anderson, 1949). Su origen está en Francia en el primer cuarto de dicho siglo (Anderson, 1949). Su uso se popularizó en Castilla, donde tuvo un desarrollo propio y original. La forma y la altura del cuerpo sufren cambios espectaculares durante la segunda mitad de dicho siglo. Se usaban simplemente para adornar la cabeza. A comienzos del siglo XIV ya no hay constancia de su uso.

El armazón rígido se forraba con una tela o con una banda también de tela, superpuesta en sentido horizontal. Esta banda podía ser lisa o podía estar rizada. Este tipo de bandas plisadas fueron del gusto de las mujeres de Castilla desde el siglo XI. Los bonetillos se sujetaban bajo la barbilla por medio de una barbeta (Fresneda, 2013) o de otra banda rígida dispuesta a modo de barboquejo.

Algunos de estos tocados se pueden ver, por ejemplo, en la escultura de la figura femenina tradicionalmente identificada con doña Beatriz de Suabia (1290), en la Catedral de Burgos; en el sepulcro de doña Urraca López de Haro (hacia 1270), Real Monasterio de Cañas, La Rioja; en el sepulcro de doña Inés Téllez Girón (finales del siglo XIII), Santa María de Villalcázar de Sirga, Palencia; o en las miniaturas de las Cantigas de Santa María de Alfonso X el Sabio (hacia 1280-85), Real Biblioteca de San Lorenzo de El Escorial, Madrid.

El tocado de la ermita soriana está algo deteriorado por el paso del tiempo, aunque todavía se distingue en algunas partes como el armazón estaría rodeado horizontalmente 
por unas bandas con sus bordes rizados. Todo el tocado está sujeto bajo la barbilla por un barboquejo también confeccionado con bandas rizadas.

Este ejemplar es, por ahora, la representación más antigua que he encontrado de tocados de cuerpo alto.

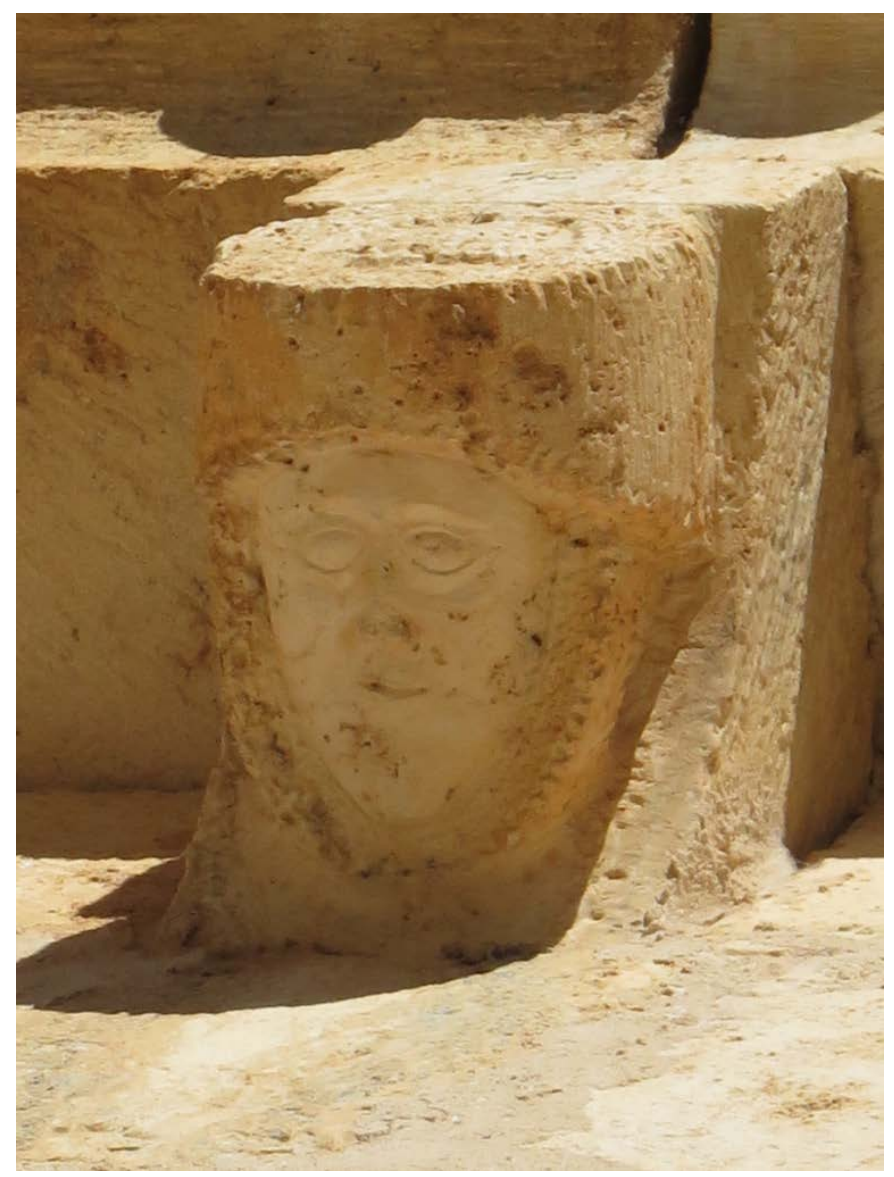

Figura 1

\section{COFIA}

Es en el siglo XII (Menéndez Pidal, 1987) cuando este término hace referencia a una prenda militar de tela o de red esférica almohadillada que llevaban los hombres para evitar que el cabello se enredara en el almófar o capiello de armar; los extremos de la cofia se unían mediante cintas bajo la barbilla. Su origen es incierto (Trias, 2012), aunque su uso es internacional.

En el siglo XIII pasa a ser prenda civil para simplemente cubrirse la cabeza, siendo empleada por todas las clases sociales. Solía ser blanca y lisa, aunque las había bordadas o de tela transparente. Exigía un trabajo específico y especializado de confección para ajustarlo a la cabeza. Su utilización decreció en el siglo XV.

Podemos ver cofias en el Monasterio de Santa María la Real de las Huelgas, Burgos, la perteneciente a don Fernando, Infante de Castilla (fallecido en 1211); en el sepulcro 
del obispo Martín (1249), en la Catedral de León; o en las Cantigas de Santa María, obra que he mencionado antes.

El personaje de la ermita luce una cofia de tela anudada bajo la barbilla con una lazada. El peinado que lleva ya se estilaba a finales del siglo XII: melena corta rematada en un bucle y flequillo formado por bucles o ricitos a la moda francesa (Bernis, 1956).

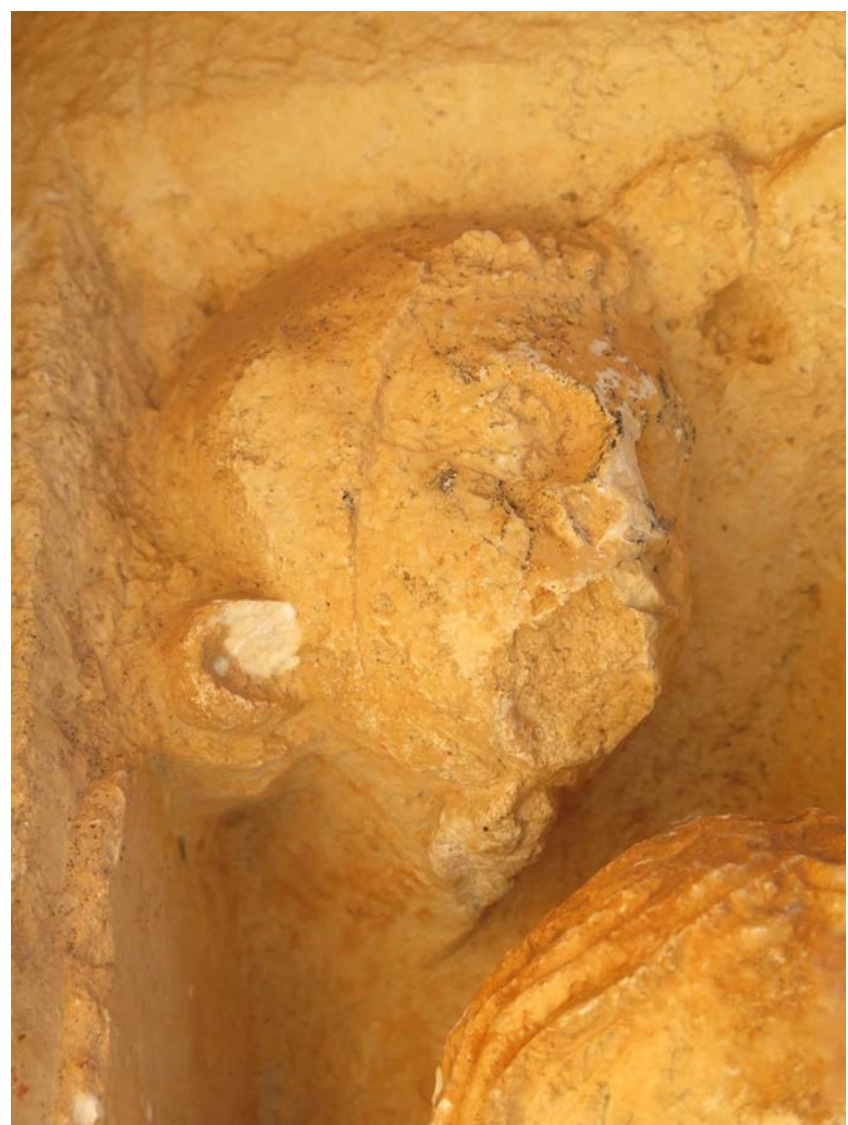

Figura 2

\section{CAPIROTE}

Documentado en la segunda mitad del siglo XIII (Astor, 1999), aunque ya se observan capirotes en la iconografía desde el siglo XII. Su origen es internacional y fue usado por los hombres de todas las capas sociales para protegerse de las inclemencias del tiempo. En el siglo XIV lo usaran también las mujeres.

El capirote surge como una prenda independiente para cubrirse la cabeza al separarse la capucha del manto o del sobretodo. Terminaba más o menos en punta. Podía ir cerrado bajo la barbilla o podía ir completamente abierto. En el siglo XIII se empezó a llevar este tocado colocando la abertura destinada a encuadrar el rostro directamente sobre la cabeza, dejando que la parte destinada a cubrir los hombros cayese por detrás o a un lado y la punta de su extremo quedara en dirección opuesta. Durante el siglo XIV y XV la prenda sufrirá transformaciones significativas que le darán formas más o menos sofisticadas. 
Capirotes podemos ver en la iglesia parroquial de San Blas (mediados del siglo XII), Nafría la Llana, Soria; en el sepulcro del Chantre Aparicio Guillén, hacia 1274, en la Catedral Vieja de Salamanca; o en el Libro de los Juegos: ajedrez, dados e tablas; Ordenamiento de las tahurerías de Alfonso X, Rey de Castilla, en la Real Biblioteca del Monasterio de San Lorenzo de El Escorial, Madrid.

En la ermita se observan dos capirotes: Uno puesto según el modo natural, y el otro, pese a su mayor deterioro, se aprecia que va dispuesto con la abertura destinada a encuadrar el rostro directamente sobre la cabeza. Así, en el contexto social anteriormente descrito de la Corona de Castilla, surge este tratado educacional Jardín de nobles doncellas. Martín de Córdoba le debió hacer entrega a Isabel de este compendio en torno a la Concordia de Guisando (1468), donde la posición de la infanta quedó altamente reforzada como legítima sucesora y futura propietaria de los reinos de Castilla y de León. Por aquel entonces parecía claro que el devenir de la Corona de Castilla era estar regida por una mujer; por tanto, no había mejor forma para legitimar este hecho que escribiendo un tratado realzando las cualidades femeninas, pero sin dejar de lado sus flaquezas (de necesaria superación).

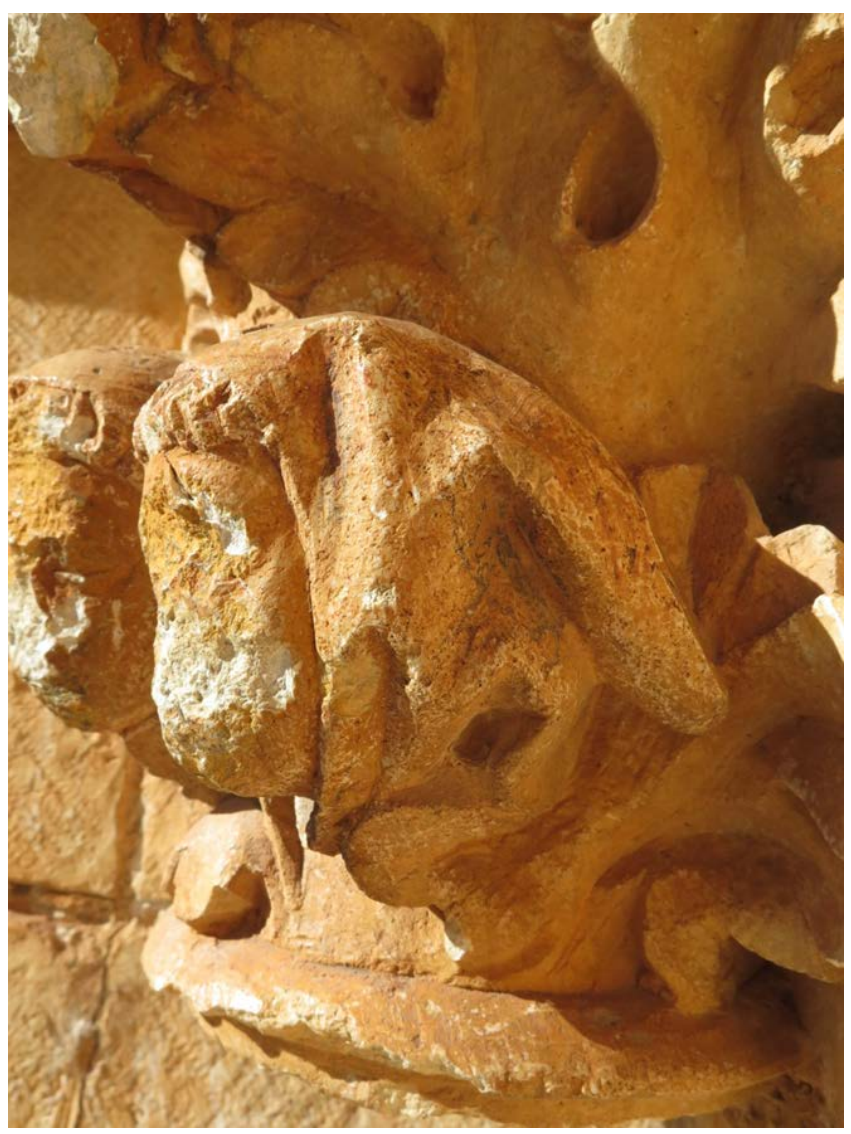

Figuras 3 


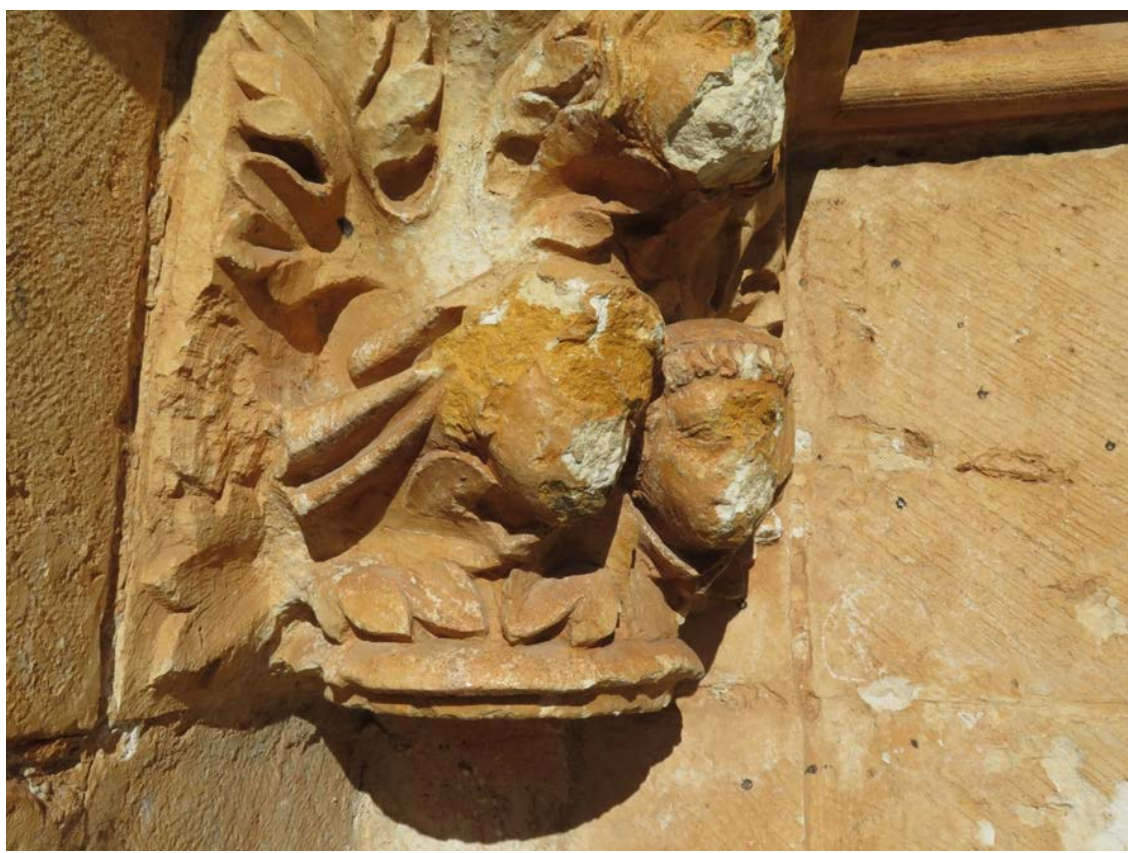

Figura 4

\section{CONCLUSIONES}

Tanto los hombres como las mujeres de la Edad Media cuidaban mucho su indumentaria al ser un potente vehículo de transmisión de status y poder. En este sentido los tocados fueron singularmente imaginativos, porque permitían a su portador destacar e individualizarse. Castilla se convierte en el siglo XIII en una pasarela de moda muy dinámica, hasta el punto de que en una ermita aislada soriana aparece un bonetillo tan del gusto de las mujeres castellanas, y que posiblemente sea la representación iconográfica más temprana hasta ahora encontrada.

\section{REFERENCIAS BIBLIOGRÁFICAS}

ACUERDO 25/2015, de 7 de mayo, de la Junta de Castilla y León, por el que se declara la Ermita de San Bartolomé en Ucero (Soria), Bien de Interés Cultural con categoría de Monumento. Obtenido de http://bocyl.jcyl.es/html/2015/05/11/html/BOCYL-D11052015-16.do

Anderson, R.M. (1949). Tocados plisados de Castilla y de León en los siglos XII y XIII [2], Boletín de la Comisión Provincial de Monumentos y de la Institución Fernán González de la ciudad de Burgos. Burgos: Diputación Provincial de Burgos, $4^{\circ}$ trim. Año 28, n. 109, 341-344.

Astor Landete, M. (1999). Indumentaria e Imagen - Valencia en los siglos XIV y XV. Valencia: Ayuntamiento de Valencia, 366.

Bernis Madrazo, C. (1949). El tocado masculino en Castilla durante el último cuarto del siglo XV. Archivo Español de Arte, Tomo 22, No 86. Pp. 111-136.

Bernis Madrazo, C. (1956). Indumentaria medieval española. Madrid Instituto Diego Velázquez, Consejo Superior de Investigaciones Científicas, 87. 
Bernis Madrazo, C. (1979). Trajes y modas en la España de los Reyes Católicos, Vol. II: Los hombres. Madrid: Instituto Diego Velázquez del Consejo Superior de Investigaciones Científicas (Arte y Artistas), 175.

Enríquez de Salamanca, C. (1998). Ruta del románico en la provincia de Soria. CodexRom, 144

Fresneda González, Mª N. (2013). Atuendo, aderezo, pócimas y ungüentos femeninos en la Corona de Castilla, (siglos XIII y XIV). Tesis doctoral, Universidad Complutense de Madrid, Facultad de Geografía e Historia, Departamento de Historia del Arte I., 1166.

Gómez Moreno, M. (1946). El Panteón Real de las Huelgas de Burgos. Madrid: Consejo Superior de Investigaciones Científicas. Instituto Diego Velázquez, 112.

Menéndez Pidal, G. (1987). La España del siglo XIII: leída en imágenes. Madrid: Real Academia de la Historia, 319.

Sigüenza Pelarda, C. (2000). La moda en el vestir en la pintura gótica aragonesa. Institución "Fernando el Católico". Zaragoza: C.S.I.C, Excem. Diputación de Zaragoza, 257.

Trias Ferri, L. (2012). La terminología tèxtil a la documentación llantina de la Catalunya altomedieval. Tesis doctoral, Universitat de Barcelona, 519. 